\title{
UN ASPECTO SIDERAL
}

Fernando de León*

\section{Resultaba inverosímil que un aliení-} gena hubiera posado para la cámara fotográfica y, sin embargo, la forma en la que sonreía, su enorme cabeza girada a tres cuartos para enfrentar con el rostro la luz mortecina de la tarde, la mano derecha puesta sobre su insignificante cadera, y la rodilla izquierda flexionada descargando la mayor parte de su peso en su otra delgada pierna, daban esa impresión.

A lo largo de mi carrera como agente del Buró de Investigaciones Paranormales he visto muchas fotografías extrañas que pretendían demostrar lo indemostrable: Pie Grande en plena huída entre abetos que sólo permiten ver un par de glúteos afelpados; un ala de hada entre hojas de maple revueltas como un campo de batalla; el mínimo reboso, quizá de una duende infiel, atorado en la punta de un maguey; imposturas que siempre hablaban, en su fraudulento discurso, de seres en fuga. Nunca había contemplado la calma gozosa de un marcianito modelando para una lente.

Yo debía investigar la autenticidad de esta fotografía y para ello me trasladé a Las Cruces, Nuevo México, desde donde alguien había enviado anónimamente la fotografía y donde también había comenzado ya el rumor de que una comunidad extraterrestre se había instalado en los alrededores.

\footnotetext{
* Escritor.
} 
Por experiencia sé que presentarme ante las autoridades de un lugar y mostrar una mínima pizca de curiosidad sobre un asunto basta para que todo acceso a la información me sea denegada o intercambiada por pistas falsas. Los dos errores de un investigador de lo paranormal son actuar con la lógica de un policía o de un científico, y tener prisa. Así que al llegar a la ciudad me instalé con toda calma en un hotel como el más torpe de los turistas preguntando solamente cuál era la comida típica y para dónde estaba el baño. Sabía que si me comportaba como un turista crédulo se me aparecería el fotógrafo de aliens que nunca se le acercaría al agente del gobierno.

Sin embargo, me pasé dos semanas sin hacer nada más que deambular con un auto rentado, tomando fotos del paisaje y comprando uno que otro suvenir. Mandaba postales a mis jefes diciéndoles que los extrañaba mucho y que la ciudad era hermosa. Ellos, quienes ya sabían de mi método, interpretaban que la investigación de campo iba en proceso.

A la tercera semana de no obtener ningún resultado, tomé el teléfono y pedí comida china y una "dama de compañía"; a dos números telefónicos diferentes, por supuesto. La mujer que llegó se abalanzó para comerse mi rollito bañado en salsa dulce. Tenía mucho apetito y lo justificó contándome que se encontraba felizmente embarazada, aunque no se le notara. No tuvimos relaciones sexuales, claro está, pero igual le pagué lo acordado con tal de platicar con ella. Sucede que las prostitutas conocen como pocos la ciudad tras bambalinas y saben todo lo que un guía de turistas ignora.

Ella me contó, con legítimo horror, que en los últimos años algunas de sus compañeras habían desaparecido, y que reaparecían luego de meses diciendo que habían sido secuestradas por extraterrestres. No logré que me diera datos precisos de alguna de las abducidas, pero me pareció interesante todo lo que me dijo. Se fue llevándose el arroz frito para comerlo más tarde y me dejó pensando por qué motivo los extraterrestres estaban especialmente interesados en abducir prostitutas.

Cuando la volví a buscar, a mediados de la cuarta semana, me dijeron que se había marchado sin decir nada, que había desaparecido. Los solícitos proveedores ofrecieron mandarme a otra muchacha, pero rechacé el servicio. 
Hubiera sido feliz pensar que la prostituta en cuestión había dejado el oficio para tener un embarazo saludable, pero mi experiencia en lo paranormal, y también en lo normal, me lleva siempre a descartar lo feliz: entonces, la prostituta ausente había sido abducida por extraterrestres.

Las Cruces es una ciudad desértica, lo que significa que no hay muchos sitios dónde esconderse; por otra parte, allí, donde abunda la soledad del desierto es siempre un insospechado e idóneo escondite. Así que tomé el carro, llené el tanque de gasolina y mirando el mapa de carreteras me lancé en dirección de uno de los pocos rumbos donde no había gasolineras. Conduje hasta que se me agotó el combustible y ahí abandoné el auto. Tenía conmigo un abrigo, una linterna y una brújula; también libreta y lápiz. Una vez que me ubiqué, me dirigí hacia donde no había poblado alguno por el desierto implacable, racionando el agua que tenía conmigo. Caminé con la mayor regularidad que pude, contando mis pasos para calcular la distancia que recorría. Si encontraba algo quería saber dónde lo había encontrado. Mi objetivo era llegar a un punto al que nadie en su juicio iría.

Por la noche el desierto se puso gélido y por la madrugada me sentí agotado. Comencé a desesperarme y a recordar las muchas ocasiones en que mi método no me condujo a ninguna parte, como las ocho semanas que pasé montado en un globo aerostático con un ancla enclavada en el centro del lago Ness, comiendo sólo carne seca y ron, esperando que el monstruo del lago asomara por lo menos la cola.

Entonces vi una luz tenue en la distancia. Era un hombre que caminaba hacia mí. Recuperando mi actitud de turista extraviado fui a su encuentro, pero a pocos metros me sorprendió que movía la linterna igual que yo. Era yo.

Me encontré ante un enorme espejo de aproximadamente dos metros de alto y unos veinte de largo. Al llegar al borde me di cuenta de que continuaba otros veinte metros de manera perpendicular. Lo rodeé; era un cubo de espejo, o mejor dicho, era una finca forrada de espejo, lo que la hacía invisible de día y de noche, pues multiplicaba por cada cara la monotonía desértica del paisaje. Seguramente, estaba orientada de tal manera que el reflejo del sol nunca la delatara. 
Busqué una puerta. En lugar de ella encontré una escotilla entre matorrales. Estaba abierta y me metí. Por dentro parecía más un submarino que un búnker: había pasillos, escaleras y pequeños cuartos por todas partes. Alguien con un poco más de imaginación pensaría que se había internado en las entrañas de un ovni, pero yo de inmediato reconocí el olor humano del encierro. Encontré uniformes de enfermero, redes para el pelo y tapabocas, me vestí así para curiosear con más calma. Seguramente por lo temprano de la hora había muy poca actividad, pero la había: en una habitación encontré a una mujer dormida sobre una cama de hospital; tenía un raro arnés apretando su vientre y una hoja al pie de su cama que decía "Semana 16". Y en cada habitación encontré mujeres dormidas con el mismo arnés en el vientre y diferentes señalamientos temporales: "Semana 24" "Semana 36" "Semana 18". Me detuve cuando encontré a la prostituta que había devorado mi comida china. Estaba en la misma circunstancia que las otras y su hoja decía "Semana 14". Movido por una inquietud algo afectiva intenté despertarla, pero por más que la zarandeé fue imposible. Inferí que estaba narcotizada. Salí del cuarto cuando escuché pasos que se aproximaban. Me oculté tras la puerta y un enfermero altísimo entró, verificó el pulso de la mujer y salió sin verme.

Quería entender qué era lo que pasaba pero todavía no tenía elementos. Era momento de salir y volver con mis compañeros agentes para desentrañar el misterio de aquello que, fuera lo que fuera, era clandestino. Sin embargo, después de haber sido tan minucioso para no desorientarme en el desierto, me di cuenta de que estaba perdido dentro de la finca. Empecé a caminar sigilosamente, buscando el camino de salida, cuando escuché voces aproximándose. Abrí la primera puerta que encontré y me metí en un cuarto obscuro. Encendí la lámpara y me encontré ante un pequeño ser alienígena que me miraba con curiosidad. Era idéntico al de la fotografía: cabeza alargada y sin cabello, brazos y piernas muy delgados, torso contrahecho. Estaba sentado en una cama. Me di cuenta de que toda la habitación estaba repleta de camas literas y que en cada una dormía un alienígena.

- Hola - me dijo- me llamo Twenty. ¿Y tú?

-Olsen - contesté de una forma automática sin poder creer que platicábamos. 
-Quiero leche con chocolate. Sé que debí tomarla en la comida, pero entonces no tuve ganas. Eleven me estuvo molestando ¿Me puedes dar leche con chocolate, por favor?

Su petición me hizo aterrizar. Pese a la penumbra y lo extraño de la circunstancia, estaba ante un niño, un niño deforme pero totalmente humano.

- Tendré que ir a buscarla — le dije.

-Está bien. Aquí te espero. No me dormiré hasta que vengas con mi leche con chocolate.

Salí del cuarto pero afuera me esperaban tres hombres altos: dos muy corpulentos y jóvenes que me sujetaron y uno de aspecto mayor y barba entrecana.

Me llevaron a otra habitación y me sentaron en una silla a la cual me ataron. Yo sólo atiné a decir:

- Twenty está esperando su leche con chocolate.

El hombre de barba escuchó eso atentamente y le hizo un gesto a uno de los forzudos, quien salió inmediatamente, seguro a buscar la bebida. El otro gigante se quedó detrás de mí y el barbón se sentó delante y comenzó a hablar.

-Es claro que ya sabe lo que hacemos. Ha visto a las prostitutas en coma y el arnés que va dando forma al feto que gestan. Cuando nazcan, si no mueren...

—Serán como Twenty. Humanos con aspecto alienígena ¿Por qué deformarlos, señor...?

—Wells. No es mi nombre, pero puede llamarme así.

—Wells ¿Para qué quiere niños deformes?

-No son deformidades, intruso cuyo nombre no me importa. Es modelaje. Son esculturas vivientes, tendrán la figura que el ideal popular denomina anatomía extraterrestre. Son parte de una leyenda que debe perdurar. No sólo este país quiere creer en aliens: todo el mundo desea con vehemencia la proximidad de seres extraterrestres.

-Déjeme adivinar: acabo de dar con otra oficina secreta del gobierno, aún cuando el mismo gobierno me mandó a investigar lo que pasa aquí. 
—Está más perdido de lo que pensaba. Ningún gobierno nos patrocina. Nos hemos instalado aquí por ser la nación más crédula del planeta, pero somos una organización independiente interesada en alimentar, en el imaginario colectivo, la propia creencia en los aliens; Roswell fue un éxito. Ahora, mi querido desconocido, lo induciremos en estado de coma y cuando despierte, si despierta, al igual que esas prostitutas que nadie extraña, no recordará nada y en el mejor de los casos pensará que fue abducido.

El grandulón a mi lado me desató. Sentí sus brazos como tenazas de acero casi quebrarme un brazo al hacerlo. Sabiéndome perdido reconocí que mi método de investigación tenía una enorme falla: que era muy difícil para mis jefes seguir mi rastro y que si yo no sobrevivía la investigación se iba al traste.

En un último gesto de revancha, bárbaro y desesperado, en nombre de las mujeres en coma y de los pequeños deformados, empuñé lo único que podía usar como arma: mi lápiz, y lo clavé en un costado de Wells.

Lo que pasó a continuación fue mucho más extraño que lo que había visto en toda mi vida: Wells gruñó, miró el lápiz en su costado y todo su cuerpo se derritió ante mis ojos, convirtiéndose en abundante pasta verde.

El gigantón me miró despavorido.

— ¡No, no me haga lo mismo! — gritó- ¡Yo les envié la fotografía de Twenty! Quería que alguien viniera. No estoy de acuerdo con esto. Las mujeres sufren, los niños mueren a corta edad.

Entendí en un parpadear que Wells había sido alienígena al igual que lo era el gigantón y que este último era mi aliado, pero que incluso con todas sus buenas intenciones, podría hacer muy poco por los niños, las mujeres o por mí, cuando llegaran los demás de su especie. Salí del lugar y me alejé lo más rápido que pude.

27 horas más tarde, cuando volví con refuerzos y nueve helicópteros, ya sólo había una finca deshabitada e incendiada. No se encontraron cadáveres.

Entre los papeles quemados encontramos media fotografía donde se alcanza a ver a Wells rodeado de niños deformados como aliens. La adjunté a mi reporte con una nota personal: "Evidencia del aspecto verdadero de un extraterrestre. Su organismo no tolera el carboncillo, incluso en cantidades mínimas, como la punta de un lápiz”. 